\title{
Rock Stress Sensitivity and its Influence on Productivity of Overpressured Gas Reservoir: A Case Study in Yinggehai Basin, China
}

\author{
Peng Xiaodong ${ }^{1,3}{ }^{\text {* }}$, Lu Yan ${ }^{1}$, Liu Xin ${ }^{1}$, Duan Ce ${ }^{1}$, Li Zhengjian ${ }^{1}$, Liu Shijie ${ }^{2}$, Tong Luyi ${ }^{1}$ \\ ${ }^{1}$ CNOOC Ltd._Zhanjiang Research Institute, Zhanjiang, Guangdong, China \\ ${ }^{2}$ CNOOC Energy Technology \& Services Ltd. Drilling \& Production Company, Tianjin, China \\ ${ }^{3}$ Postgraduate, petroleum engineer, engaged in reservoir engineering and reserve evaluation, CNOOC Ltd._Zhanjiang Research Institute, \\ Zhanjiang, Guangdong, China
}

\section{Email address:}

pengxd@cnooc.com.cn (Peng Xiaodong), luyan15@cnooc.com.cn (Lu Yan), liuxin13@cnooc.com.cn (Liu Xin), duance@cnooc.com.cn (Duan Ce), lizhj17@cnooc.com.cn (Li Zhengjian), liushj23@cnooc.com.cn (Liu Shijie), tongly@cnooc.com.cn (Tong Luyi)

\section{To cite this article:}

Peng Xiaodong, Lu Yan, Liu Xin, Duan Ce, Li Zhengiian, Liu Shijie, Tong Luyi. Stress Sensitivity of Rock and its Influence on Productivity for Overpressured Gas Reservoir: A Case Study in Yinggehai Basin, China. International Journal of Oil, Gas and Coal Engineering.

Vol. 3, No. 3, 2015, pp. 33-40. doi: 10.11648/j.ogce.20150303.11

\begin{abstract}
H}$ gas reservoir is an overpressured gas reservoir with high temperature. It is generally believed that overpressured gas reservoir exist stress sensitivity effect due to uncompaction. Firstly, this study conducted lab core test to analysis stress sensitivity of rock by defined confining pressure and decreasing inner pressure. Test results show that the reservoir processes weak to medium stress sensibility. Then, according to mineral composition analysis and strain-stress curve comparison of the cores, stress sensibility is considered to be mainly caused by low hardness clay mineral. Finally, based on well testing data of well H-X-1, we used pseudo-pressure binomial deliverability equation considering stress sensitivity to discuss the influences of stress sensibility on productivity. Results show that the stronger the stress sensibility is, the more obviously productivity decreases. As stress sensibility of the block is weak to medium, it has little impact on productivity.
\end{abstract}

Keywords: Abnormal High Pressure, Gas Reservoir, Stress Sensitivity, Productivity, Yinggehai Basin

\section{Introduction}

With abnormal pressure and high temperature, $\mathrm{H}$ gas reservoir is located in Yinggehai Basin of western South China Sea. With a burial depth of 3000 meters, its temperature is above $140^{\circ} \mathrm{C}$, and pressure is higher than $50 \mathrm{MPa}$. Pressure coefficient is 1.88 to 2.09 , and temperature gradient is $4.17^{\circ} \mathrm{C}$ $/ 100 \mathrm{~m}$ to $4.39^{\circ} \mathrm{C} / 100 \mathrm{~m}$. Overburden pressure is about 70 $\mathrm{MPa}[1,2]$. Current thinking suggests that in overpressure gas reservoir, rock is in under compaction condition. Therefore in depletion development process effective stress of rock skeleton greatly increases, which will cause prominent elastic-plastic deformation of the rock, and then produce stress sensibility $[3,4]$.

Currently reservoir stress sensibility evaluation test mainly use method of defined inner pressure while changing confining pressure [5]. But this experiment is mainly used for overburden pressure correction of reservoir porosity and permeability [6]. Stress variation of underground reservoir is actually caused by pressure variation of pore fluid. So use more reasonable method of defined confining pressure while changing inner pressure [6]. About productivity evaluation, some steady and pseudo-steady productivity equations considering stress sensitivity are established $[7,8]$. However, those equations are established on pressure form, and need more calculation parameters, so the error is larger. This study use pseudo-pressure considering stress sensibility to evaluate productivity $[9,10]$. This method can linearize deliverability equation. Then get open flow capacity according to regression line, which can eliminate errors caused by reservoir parameters uncertainty. 


\section{Stress Sensitivity Test of Abnormal High Pressure Gas Reservoir}

\subsection{Experiment Process}

To simulate stress variation of underground reservoir more truly, we use the method of defined confining pressure and changing fluid pressure. The experimental instrument is high temperature and high pressure core flow instrument (a temperature of $200^{\circ} \mathrm{C}$ and a pressure of $70 \mathrm{MPa}$ ) produced by USA core company [6]. Permeability testing temperature is $140^{\circ} \mathrm{C}$; Confining pressure is $70 \mathrm{MPa}$; Initial pressure of gas reservoir is 55 to $5 \mathrm{MPa}$, and net overburden pressure is 15 to $65 \mathrm{MPa}$.

Firstly saturate core with nitrogen, and make two independent hydrostatic pressure systems in core holder, which means confining pressure and inner pressure. In the test, hold confining pressure unchanged. Firstly decreasing inner pressure gradually and get permeability under the corresponding pressure. When inner pressure falls to minimal designing point, increase it gradually and test the corresponding permeability until it rises to maximal designing point. Following figure (1) shows experimental flow chart.

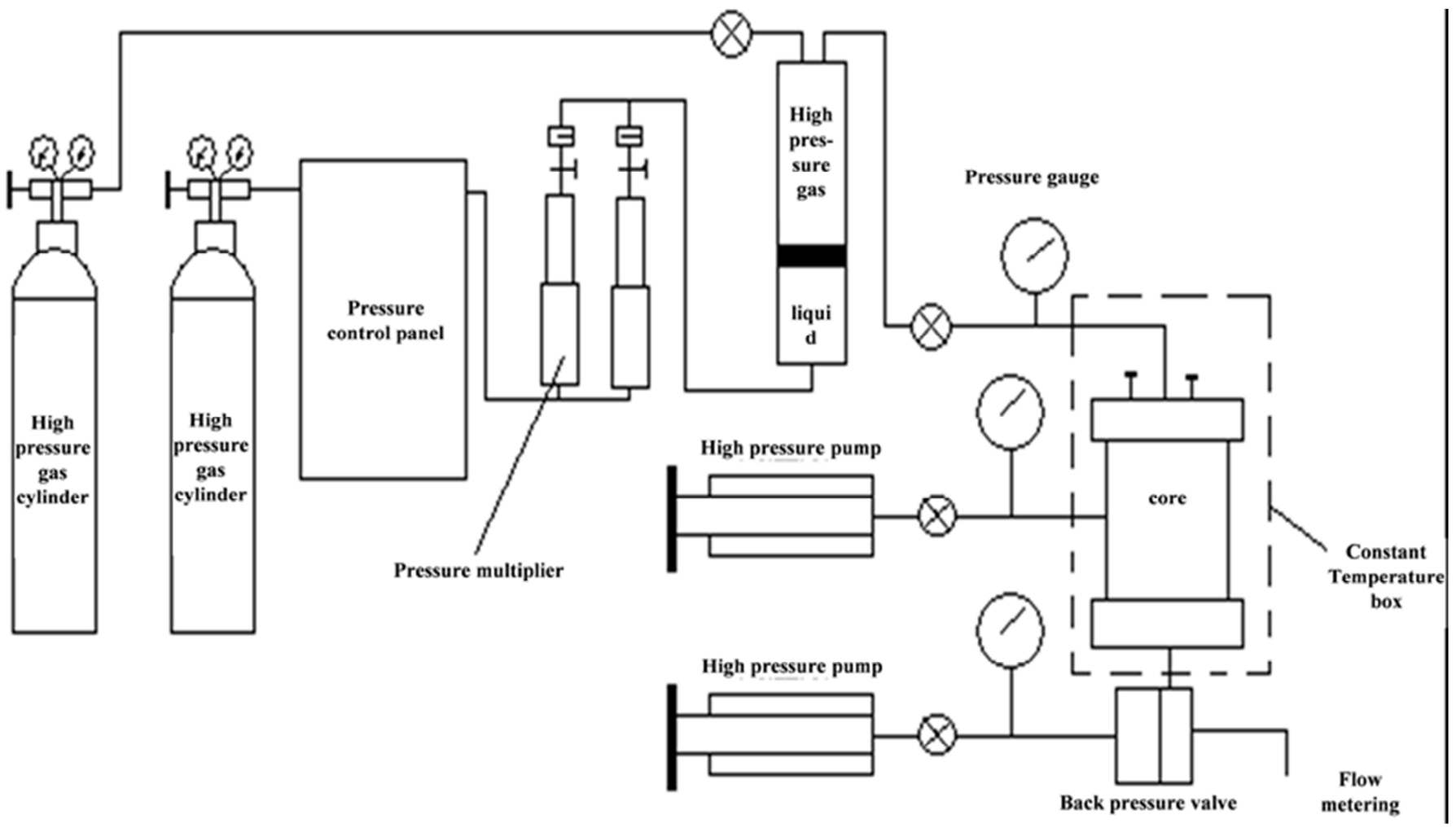

Figure 1. Permeability stress sensibility test process on high temperature and high pressure core flow instrument.

\subsection{Experiment Result}

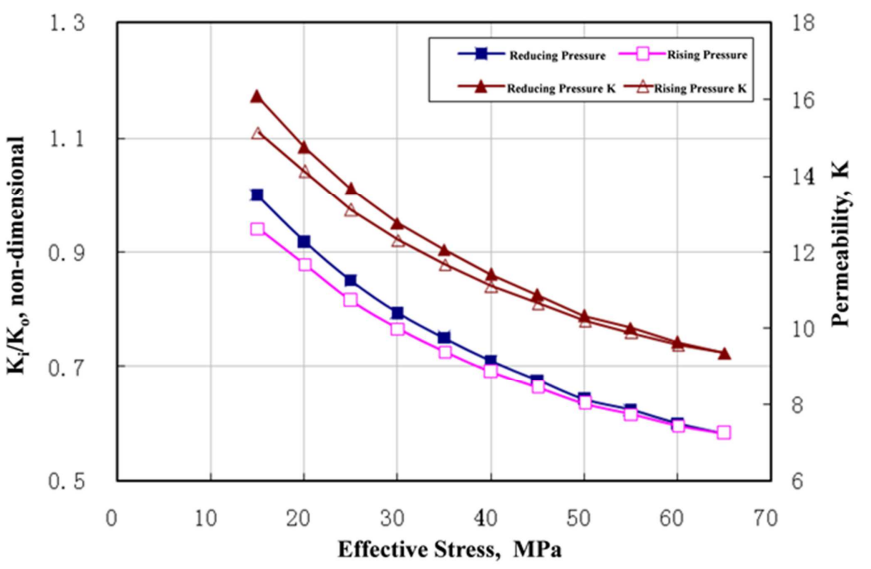

(a)No.1 core

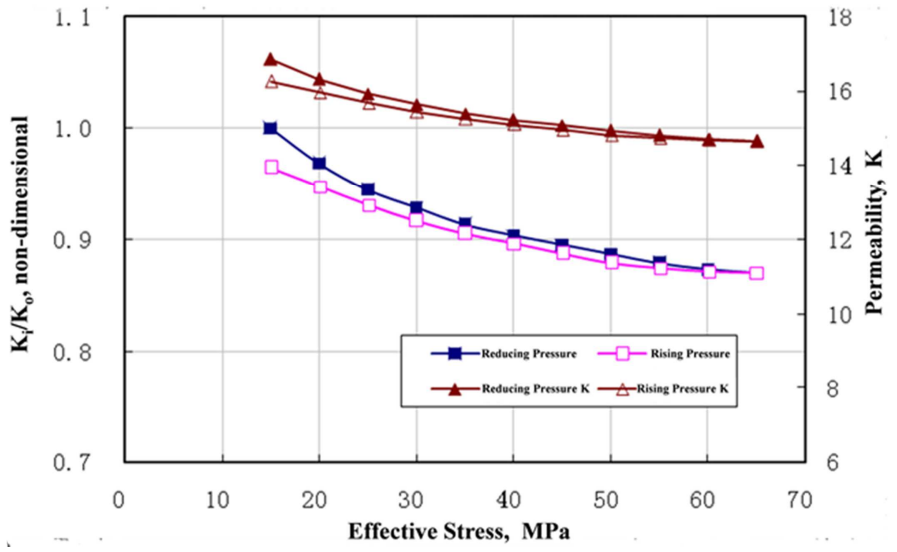

(b)No.1-1 core

Figure 2. Permeability variation of stress sensibility experiment. 
Experimental result (Figure 2) shows that: (1) pressure increasing curve and decreasing curve do not coincide. It means permeability variation is irreversible; (2) permeability decreases with increasing effective pressure. Decline rate is greater during early stage, and it becomes smaller during later stage. Therefore when develop abnormal high pressure gas reservoir, we should guarantee continuous flowing production and avoid shut in during producing to avoid irreversible change of rock, especially in early developing stage.

Stress sensibility intensity of abnormal high pressure reservoir is generally presented by stress sensibility coefficient and permeability damage ratio. Definition of stress sensibility coefficient is showed in equation (1), in which $\alpha$ is stress sensibility coefficient and its unit is $\mathrm{MPa}^{-1}$. The bigger $\alpha$ is, the more intense stress sensibility is. When $\alpha=0$, stress sensibility disappear[8]. According to equation (1) $[15,16]$, there lies in an exponential relationship between permeability and pressure drop. Logarithmic both sides of the equation (2), Using stress sensibility data, can get relationship curve of $\ln K \sim \Delta p$. And the slope of line fitting by the curve is $\alpha$.

$$
\begin{gathered}
\alpha=\frac{1}{K} \frac{\partial K}{\partial p} \\
K=K_{i} e^{-\alpha\left(p_{i}-p\right)}
\end{gathered}
$$

Calculation equation of permeability damage ratio [6] is as following equation (3). $D_{k}$ is permeability damage ratio. When $\mathrm{D}_{\mathrm{k}} \leq 0.3$, reservoir performs weak stress sensibility; when $0.3<$ $\mathrm{D}_{\mathrm{k}}<0.7$, reservoir performs middle stress sensibility; when $D_{k} \geq 0.7$, reservoir performs strong stress sensibility [8].

$$
D_{k}=\frac{K_{i}-K}{K_{i}} \times 100 \%
$$

Based on permeability of initial effective overburden pressure, normalize test data of core stress sensibility experiment. We can get variation curves of dimensionless permeability (Figure 3) and stress sensibility evaluation result table (Table 1). The table shows that stress sensibility coefficient of permeability is 0.001 to 0.0104 , and average value is 0.05 ; when reservoir pressure falls from $55 \mathrm{MPa}$ to $5 \mathrm{MPa}$ (pressure differential is $50 \mathrm{MPa}$ ), reservoir permeability damage ratio is $8.95 \%$ to $41.25 \%$. If reservoir pressure declines $10 \mathrm{MPa}$ [17], reservoir permeability damage ratio $\mathrm{D}_{\mathrm{k} 10}$ is $3.01 \%$ to $16.67 \%$. According to industry standard, stress sensibility degree of core permeability is weak to middle [8].

Table 1. Stress sensibility evaluation result of core permeability.

\begin{tabular}{llllll}
\hline Core NO. & $\boldsymbol{\varphi ( \% )}$ & $\mathbf{K}(\mathbf{m D})$ & $\begin{array}{l}\boldsymbol{\alpha} \\
(\mathbf{M P a}-\mathbf{1})\end{array}$ & $\mathbf{D}_{\mathbf{K}}(\mathbf{\%})$ & $\mathbf{D}_{\mathbf{K} \mathbf{1 0}}(\mathbf{\%})$ \\
\hline NO.1 & 18.45 & 13.3 & 0.0104 & 41.25 & 15.63 \\
NO.X1-3 & 20.55 & 10.05 & 0.0018 & 9.08 & 3.36 \\
NO.1-1 & 22.18 & 17.32 & 0.0027 & 13.53 & 5.29 \\
NO.X1-1 & 11.34 & 20.52 & 0.0021 & 9.62 & 3.01 \\
\hline
\end{tabular}

\begin{tabular}{llllll}
\hline Core NO. & $\boldsymbol{\varphi ( \% )}$ & $\mathbf{K}(\mathbf{m D})$ & $\begin{array}{l}\boldsymbol{\alpha} \\
(\mathbf{M P a}-\mathbf{1})\end{array}$ & $\mathbf{D}_{\mathbf{K}}(\mathbf{\%})$ & $\mathbf{D}_{\mathbf{K} \mathbf{1 0}}(\mathbf{\%})$ \\
\hline NO.1-2 & 16.09 & 20.88 & 0.0018 & 8.95 & 3.16 \\
NO.4 & 24.07 & 23.05 & 0.0042 & 19.23 & 6.92 \\
NO.5 & 20.59 & 6.49 & 0.0062 & 27.56 & 9.62 \\
NO.6 & 19.55 & 1.8 & 0.0095 & 38.33 & 16.67 \\
\hline
\end{tabular}

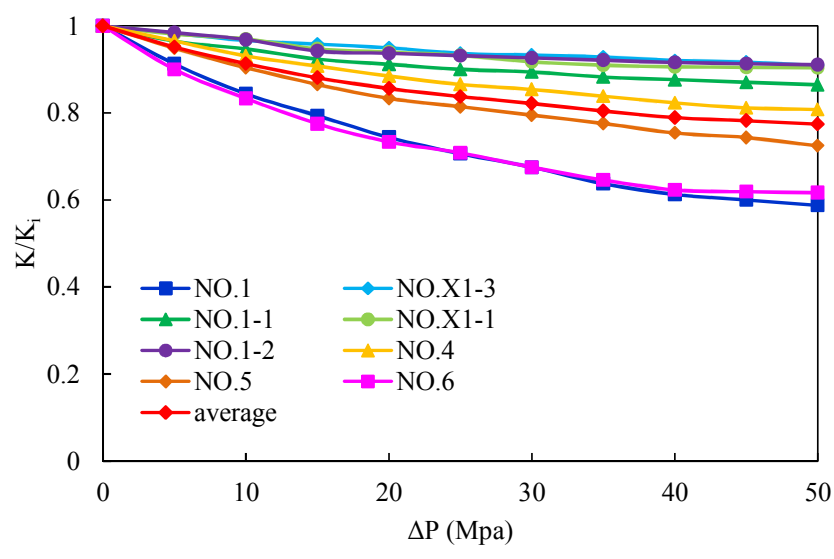

Figure 3. Stress sensibility experimental result of core permeability.

\subsection{Reasons Discussion of Stress Sensibility}

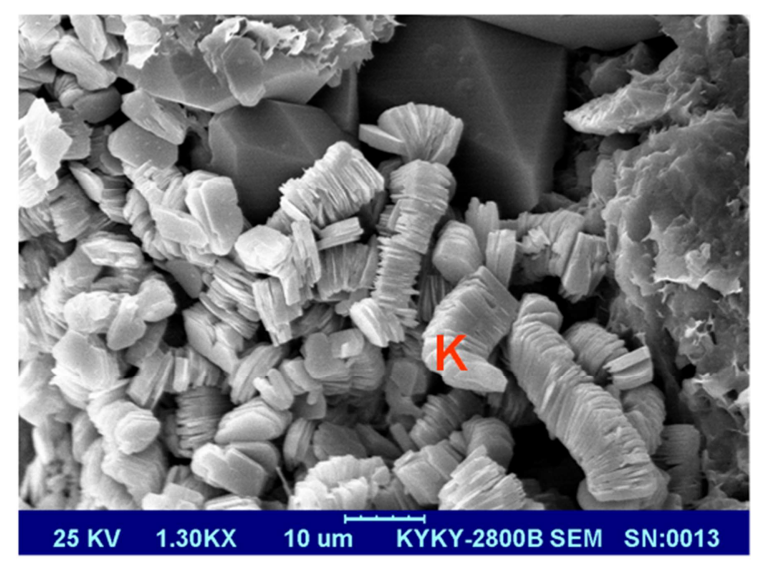

(a)Inter granular pore filling by book kaolinite (K) (magnifying 1300 times)

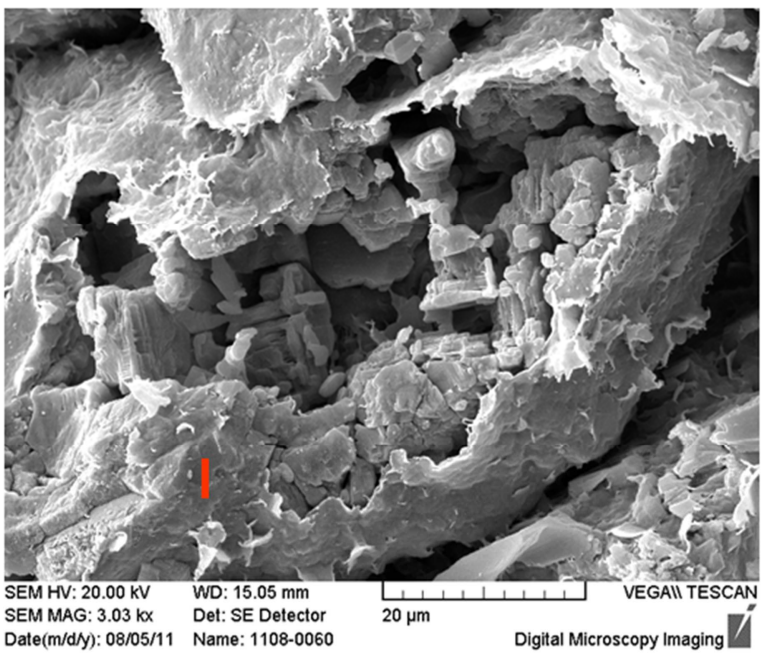

(b)Particle surface coated by flake/filiform illite (magnifying 1510 times) 


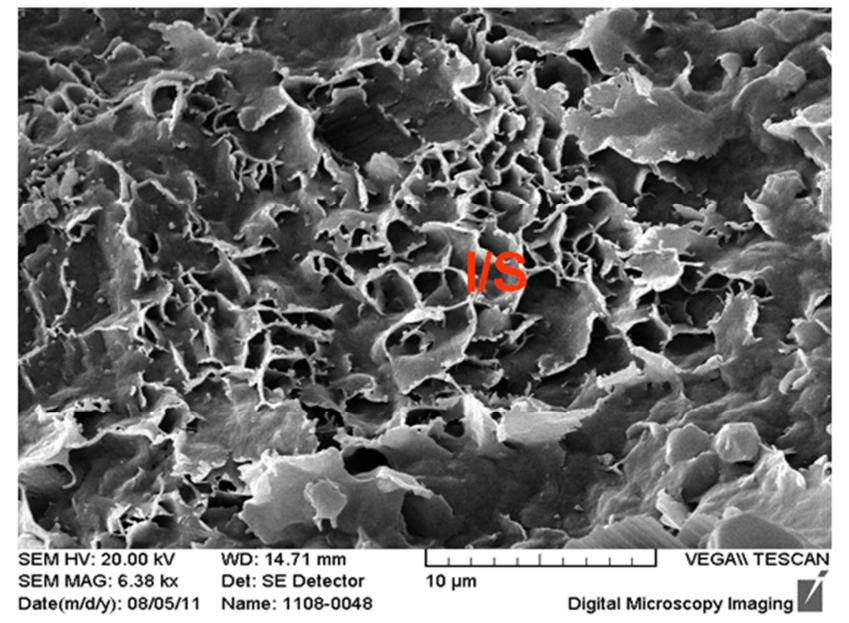

(c)I/S formation with honeycomb particle surface (magnifying 6380 times)

Figure 4. Scanning electron microscope graph of clay mineral.
Table 1 shows that stress sensibility of permeability in No.1 core is 0.0077 higher than No.1-1 core, and permeability damage ratio is $27.72 \%$ higher than No.1-1 core. According to X-ray diffraction, get mineral composition and relative clay mineral content table of No.1 and No. 1-1 core (Table 2, Table 3). Table 2 shows that quartz content of No. 1 core is $7.03 \%$ lower than No. $1-1$ core; feldspar content of No. 1 core is $7.04 \%$ higher than No. 1-1 core; clay mineral content is $1.35 \%$ higher than No. $1-1$ core, thereinto relative kaolinite content is $7.6 \%$ higher than No. 1-1 core. Mechanical property of quartz and feldspar is stable, and compressive strength is high $[18,19]$. Mechanical property of clay mineral is relatively poor, and compressive strength is relatively low $[18,19]$. However occurrence of the clay mineral is special (Figure 4), under compression particle is easily to drop and transport, then throat is blocked and permeability changes irreversibly. Clay content of No.1 core is higher than No. 1-1 core, so that stress sensibility of No.1 core is more intense than No. 1-1 core.

Table 2. Test result of core mineral composition.

\begin{tabular}{|c|c|c|c|c|c|c|c|c|c|}
\hline \multirow{2}{*}{ Well } & \multirow{2}{*}{$\begin{array}{l}\text { core } \\
\text { /depth, m }\end{array}$} & \multirow{2}{*}{$\begin{array}{l}\varphi \\
(\%)\end{array}$} & \multirow{2}{*}{$\begin{array}{l}K \\
(\mathrm{mD})\end{array}$} & \multicolumn{6}{|c|}{ Mineral content $(\%)$} \\
\hline & & & & clay & quartz & orthoclase & plagioclase & dolomite & siderite \\
\hline \multirow{2}{*}{$X-4$} & $1,2864.89$ & 18.45 & 13.3 & 12.31 & 55 & 14.24 & 14.83 & 2.06 & 1.56 \\
\hline & $1-1,2864.72$ & 22.18 & 17.32 & 10.96 & 62.03 & 3.99 & 18.04 & 2.41 & 2.57 \\
\hline
\end{tabular}

Table 3. Analysis result of relative clay content.

\begin{tabular}{|c|c|c|c|c|c|c|c|}
\hline \multirow{2}{*}{ Well } & \multirow{2}{*}{ core } & \multirow{2}{*}{$\begin{array}{l}\varphi \\
(\%) \\
\end{array}$} & \multirow{2}{*}{$\begin{array}{l}\text { K } \\
(\mathrm{mD})\end{array}$} & \multicolumn{4}{|c|}{ Relative clay content (\%) } \\
\hline & & & & illite & illite/smectite & kaolinite & chlorite \\
\hline \multirow{2}{*}{$X-4$} & 1 & 18.45 & 13.3 & 37.8 & 10.5 & 51.6 & 0.0 \\
\hline & $1-1$ & 22.18 & 17.32 & 47.8 & 9.2 & 43.0 & 0.0 \\
\hline
\end{tabular}

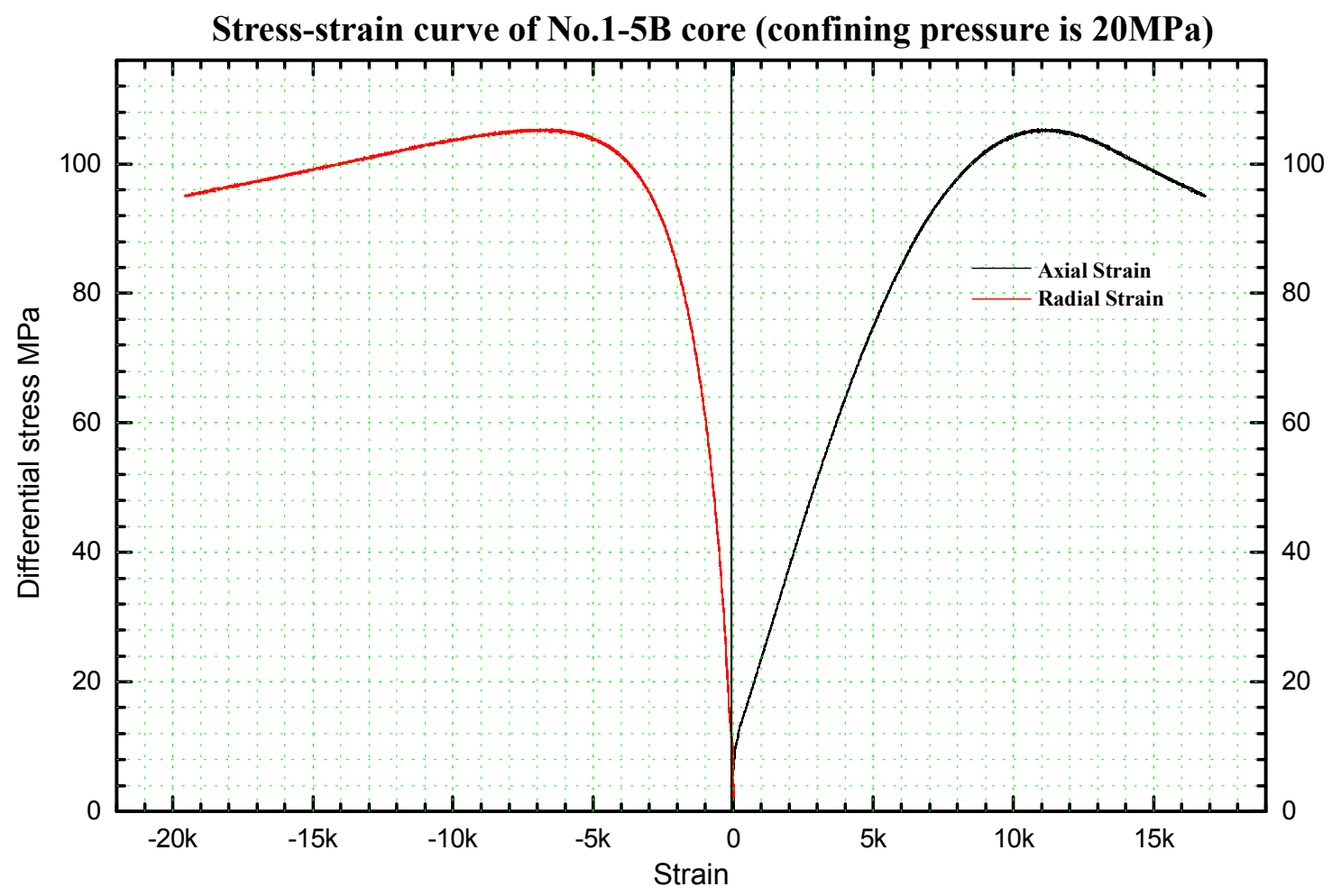

Figure 5. Stress-strain curve of sandstone. 


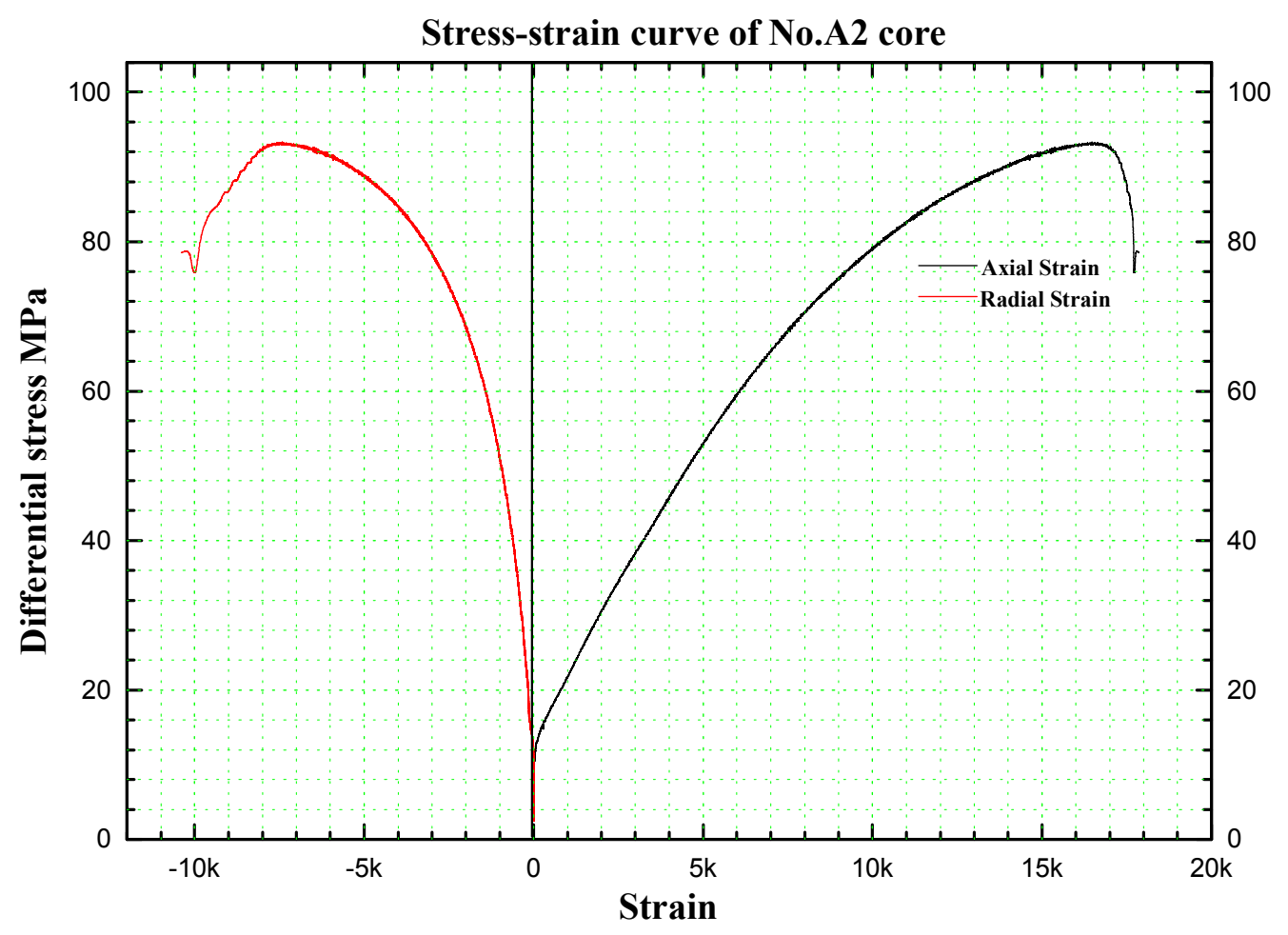

Figure 6. Stress-strain curve of gray silty mudstone.

Rock deformation process includes: elastic deformationplastic deformation- failure [18]. In elastic deformation range, permeability and porosity variation of rock is reversible. While plastic deformation occurs, permeability and porosity variation is irreversible [17]. Stress-strain curve (Figure 5) of the sandstone shows that when differential stress is less than $70 \mathrm{MPa}$, slope of axial stress-strain curve is basically a definite value, indicating elastic deformation. However, in stress-strain curve (Figure 6) of the silty mudstone, when differential stress is less than $70 \mathrm{MPa}$, slope of axial stress-strain curve is gradually increasing with the strain increasing, indicating plastic deformation. So that plastic deformation of the rock is mainly caused by plastic deformation of low hardness clay mineral.

By synthesized analyses, stress sensibility of reservoir rock is mainly influenced by clay mineral. The higher clay mineral content, the more complex occurrence is, and more intense stress sensibility is.

\section{Production Evaluation of Abnormal High Pressure Gas Reservoir}

Based on non-Darcy flow equation of gas reservoir, considering stress sensibility with different permeability, this paper builds production equation of gas reservoir $[9,10]$.

Define pseudo-pressure of stress sensibility as follows [10]:

$$
m(p)=\int_{p_{s c}}^{p} \frac{\exp \left(-\alpha\left(p_{i}-p\right)\right) \rho_{g}}{\mu_{g}} d p
$$

High speed non-Darcy flow of gas in porous media can be mathematical depicted as follows $[9,10]$ :

$$
\frac{d p}{d r}=\frac{1000 \mu_{g}}{K(p)} \frac{m_{g}}{2 \pi r h \rho_{g}}+\beta_{g} \rho_{g}\left(\frac{m_{g}}{2 \pi r h \rho_{g}}\right)^{2}
$$

Turbulence coefficient $[9,10]$ is:

$$
\beta_{g}=\frac{1.88 \times 10^{10}}{K^{1.47} \phi^{0.53}}
$$

Transform equation (5) and integrate both sides of the equation. Considering skin effect and turn mass flow into volume flow $[9,10]$, then take equation (4) into it, we can get:

$$
m\left(P_{R}\right)-m\left(P_{w f}\right)=\frac{1000 \rho_{s c}}{2 \pi K_{i} h}\left(\ln \frac{r_{e}}{r_{w}}+s\right) Q_{g}+\frac{\rho_{s c}^{2} \int_{r}^{r_{e}} \frac{\beta_{g} \exp \left[-\alpha\left(p_{i}-p\right)\right]}{\mu_{g} r^{2}} d r}{4 \pi^{2} h^{2}} Q_{g}^{2}
$$

Take non-Darcy coefficient [9] (equation 8) into equation (7):

$$
D=\frac{4.9487 \times 10^{-18} \beta_{g} M_{g} p_{s c} K}{h r_{w} T_{s c} \mu_{g}}
$$


We can get:

$$
m\left(P_{R}\right)-m\left(P_{w f}\right)=\frac{1000 \rho_{s c}}{2 \pi K_{i} h}\left(\ln \frac{r_{e}}{r_{w}}+s\right) Q_{g}+\left(\frac{\rho_{s c}^{2} r_{w} T_{s c}}{1.98 \times 10^{-7} \pi^{2} h M_{g} p_{s c} K_{i}} \int_{r}^{r_{e}} \frac{D}{r^{2}} d r\right) Q_{g}^{2}
$$

Assume:

$$
\begin{array}{r}
A=\frac{1000 \rho_{s c}}{2 \pi K_{i} h}\left(\ln \frac{r_{e}}{r_{w}}+s\right) \\
B=\frac{\rho_{s c}^{2} r_{w} T_{s c}}{1.98 \times 10^{-7} \pi^{2} h M_{g} p_{s c} K_{i}} \int_{r}^{r_{e}} \frac{D}{r^{2}} d r
\end{array}
$$

We can get:

$$
m\left(p_{R}\right)-m\left(p_{w f}\right)=A Q_{g}+B Q_{g}^{2}
$$

Equation (12) is binomial deliverability equation considering stress sensibility of gas reservoir. Coefficient A cannot reflect reservoir stress sensibility, while coefficient B can reflect effect of reservoir stress sensibility comprehensively [10].

Absolute open flow potential is:

$$
Q_{A O F}=\frac{-A+\sqrt{A^{2}+4 B\left[m\left(p_{R}\right)-m\left(p_{s c}\right)\right]}}{2 B}
$$

DST (Drill Stem Testing) data of well H-X-1 is shown in table 4. Stress sensibility data is shown in table 1. Firstly calculate pseudo-pressure considering stress sensibility under different stress sensibility coefficient by numerical integration method (Figure 7). Then through linearity regression to the $\frac{m\left(p_{R}\right)-m\left(p_{w f}\right)}{Q_{g}} \sim \mathrm{Q}_{\mathrm{g}}$ relationship curve (Figure 8) under different stress sensibility coefficient in the Cartesian coordinates. Use slope and intercept of the line to get constant $\mathrm{A}$ and $\mathrm{B}$ in the deliverability equation. Then get IPR curves (Figure 9) and absolutely open flow capacity $Q_{A O F}$ (Table 5) under different stress sensibility coefficient. With reference to the figures we can see that the more intense the stress sensibility is, the more obviously the productivity decreases. Without regard of stress sensibility, open flow capacity is $861.66 \times 10^{4} \mathrm{~m}^{3} / \mathrm{d}$; consider stress sensibility of No.1 core, open flow capacity is $769.21 \times 10^{4} \mathrm{~m}^{3} / \mathrm{d}$, and productivity loss is $10.73 \%$; consider average stress sensibility, open flow

\begin{tabular}{|c|c|c|c|c|c|c|c|c|c|c|c|}
\hline \multirow{2}{*}{ well } & \multirow{2}{*}{$\begin{array}{l}\text { Testing } \\
\text { method }\end{array}$} & \multirow{2}{*}{$\begin{array}{l}\text { Sand } \\
\text { body }\end{array}$} & \multirow{2}{*}{$\begin{array}{l}\text { Perforation } \\
\text { interval m }\end{array}$} & \multirow{2}{*}{$\begin{array}{l}\text { Effective } \\
\text { thickness m }\end{array}$} & \multirow{2}{*}{$\begin{array}{l}\text { choke } \\
\text { mm }\end{array}$} & \multicolumn{3}{|c|}{$\operatorname{production}\left(\mathrm{m}^{3} / \mathrm{d}\right)$} & \multirow{2}{*}{$\begin{array}{l}\text { Bottom hole } \\
\text { pressure } \\
\text { MPa }\end{array}$} & \multirow{2}{*}{$\begin{array}{l}\text { Extrapolation } \\
\text { pressure MPa }\end{array}$} & \multirow{2}{*}{$\begin{array}{l}\text { Producing } \\
\text { pressure } \\
\text { drop } \mathrm{MPa}\end{array}$} \\
\hline & & & & & & oil & gas & water & & & \\
\hline \multirow{5}{*}{$\mathrm{H}-\mathrm{X}-1$} & \multirow{5}{*}{ DST1 } & \multirow{5}{*}{$\mathrm{H}_{1} \mathrm{I}_{\mathrm{a}}$} & \multirow{5}{*}{$\begin{array}{l}2976.0 \sim \\
2998.9 \\
3003.5 \sim \\
3010.0\end{array}$} & \multirow{5}{*}{27.2} & 6.35 & 14.1 & 239192 & trace & 51.826 & 52.702 & 0.876 \\
\hline & & & & & 8.73 & 27.2 & 436849 & trace & 51.320 & 52.702 & 1.382 \\
\hline & & & & & 11.11 & 36.0 & 589906 & trace & 50.833 & 52.702 & 1.869 \\
\hline & & & & & 13.49 & 48.8 & 794066 & trace & 50.330 & 52.702 & 2.372 \\
\hline & & & & & 19.05 & 52.8 & 1211654 & trace & 49.470 & 52.702 & 3.232 \\
\hline
\end{tabular}
capacity is $822.17 \times 10^{4} \mathrm{~m}^{3} / \mathrm{d}$, and productivity loss is $4.58 \%$. On the whole, stress sensibility has little impact on productivity.

Table 4. Stable well testing data of well $H-X-1$ in H formation.

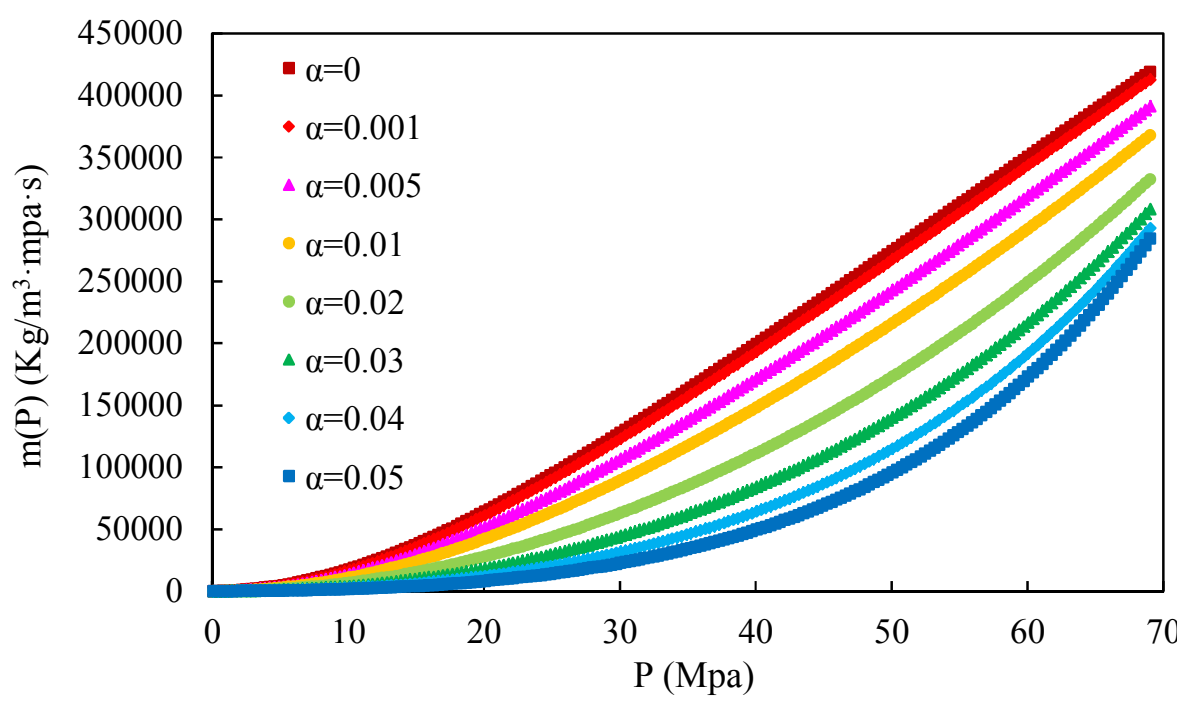

Figure 7. Relationship curve of pseudo-pressure and pressure under different stress sensibility coefficient. 


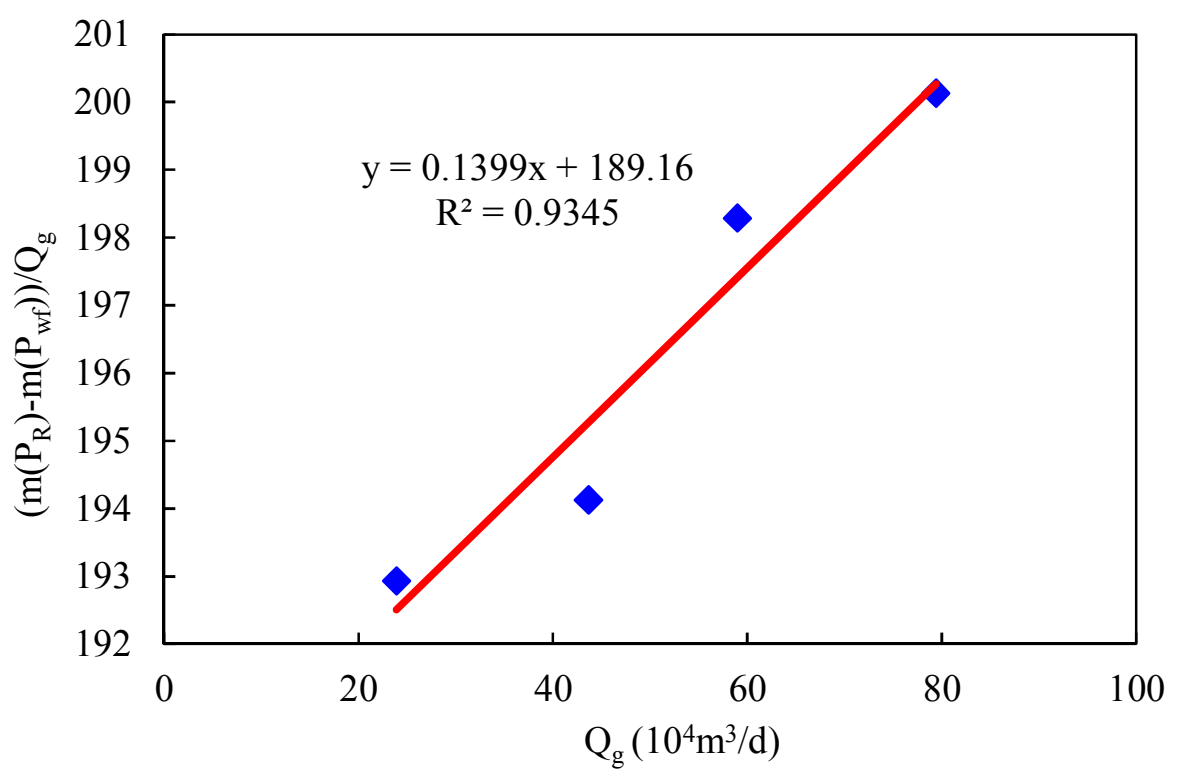

Figure 8. Binomial deliverability equation with pseudo-pressure considering stress sensibility $(\alpha=0.01)$.

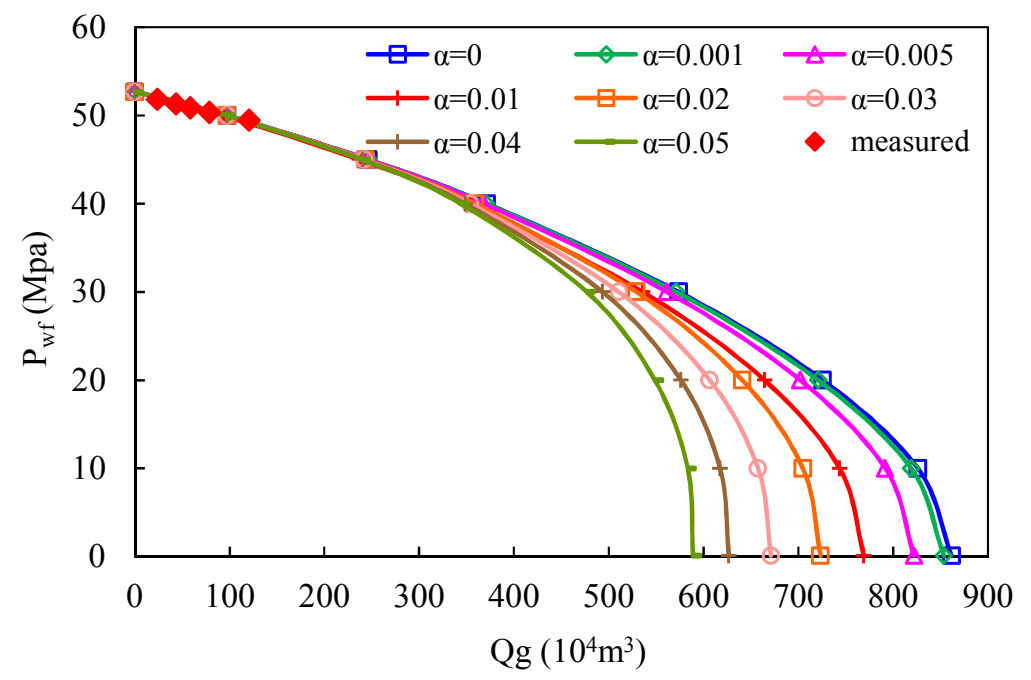

Figure 9. IPR curves under different stress sensibility coefficient.

Table 5. Deliverability calculation result with pseudo-pressure considering stress sensibility.

\begin{tabular}{llll}
\hline \multirow{2}{*}{ Equation } & $\mathbf{Q}_{\text {AOF }}$ & $\boldsymbol{\alpha}$ & $\mathbf{D}_{\mathbf{k}}$ \\
\cline { 2 - 4 } & $\mathbf{1 0}^{4} \mathbf{m}^{3} / \mathbf{d}$ & $\mathbf{M p a}^{-\mathbf{1}}$ & $\mathbf{\%}$ \\
\hline $\mathrm{m}\left(\mathrm{P}_{\mathrm{R}}\right)-\mathrm{m}\left(\mathrm{P}_{\mathrm{wf}}\right)=0.1725 \mathrm{q}^{2}+192.6 \mathrm{q}$ & 861.66 & 0.000 & 0.00 \\
$\mathrm{~m}\left(\mathrm{P}_{\mathrm{R}}\right)-\mathrm{m}\left(\mathrm{P}_{\mathrm{wf}}\right)=0.1691 \mathrm{q}^{2}+192.28 \mathrm{q}$ & 853.46 & 0.001 & 0.95 \\
$\mathrm{~m}\left(\mathrm{P}_{\mathrm{R}}\right)-\mathrm{m}\left(\mathrm{P}_{\mathrm{wf}}\right)=0.1559 \mathrm{q}^{2}+190.96 \mathrm{q}$ & 822.17 & 0.005 & 4.58 \\
$\mathrm{~m}\left(\mathrm{P}_{\mathrm{R}}\right)-\mathrm{m}\left(\mathrm{P}_{\mathrm{wf}}\right)=0.1399 \mathrm{q}^{2}+189.16 \mathrm{q}$ & 769.21 & 0.01 & 10.73 \\
$\mathrm{~m}\left(\mathrm{P}_{\mathrm{R}}\right)-\mathrm{m}\left(\mathrm{P}_{\mathrm{wf}}\right)=0.1091 \mathrm{q}^{2}+185.34 \mathrm{q}$ & 723.55 & 0.02 & 16.03 \\
$\mathrm{~m}\left(\mathrm{P}_{\mathrm{R}}\right)-\mathrm{m}\left(\mathrm{P}_{\mathrm{wf}}\right)=0.00801 \mathrm{q}^{2}+181.53 \mathrm{q}$ & 671.04 & 0.03 & 22.12 \\
$\mathrm{~m}\left(\mathrm{P}_{\mathrm{R}}\right)-\mathrm{m}\left(\mathrm{P}_{\mathrm{wf}}\right)=0.0525 \mathrm{q}^{2}+178.01 \mathrm{q}$ & 626.68 & 0.04 & 27.27 \\
$\mathrm{~m}\left(\mathrm{P}_{\mathrm{R}}\right)-\mathrm{m}\left(\mathrm{P}_{\mathrm{wf}}\right)=0.0262 \mathrm{q}^{2}+174.96 \mathrm{q}$ & 588.80 & 0.05 & 31.67 \\
\hline
\end{tabular}

\section{Conclusion and Proposals}

(1)With defined confining pressure and changing inner pressure, stress sensibility test results show that permeability of the block declines as effective stress increases. It declines quickly in the initial stage, and tends to decline slowly in the later stage. Permeability variation is irreversible, and stress sensibility degree is weak to middle;

(2)X-ray diffraction indicates that cores with intense stress sensibility always have higher clay content; rock stress-strain test indicates elastic deformation occurs in sandstone within overburden pressure, while plastic deformation occurs in silty 
mudstone. In summary, stress sensibility is mainly caused by low hardness clay mineral;

(3)Binomial deliverability equation of pseudo-pressure considering stress sensitivity indicates that the more intense reservoir stress sensibility is, the more obviously productivity decreases. In the test, the average stress sensibility reduces 5\% of the productivity, and stress sensibility has little impact on productivity.

\section{Nomenclature}

$\alpha$-Stress sensibility coefficient, $\mathrm{MPa}^{-1} ; D_{k}$ -Permeability damage ratio; $p$-Formation pressure, $M P a ; p_{i}$-Initial formation pressure, $M P a ; p_{w f}$ -Bottom hole pressure, $M P a ; p_{s c}$-Atmospheric pressure, $m(p)$-Pseudo pressure, $M P a^{2} /(m P a \cdot s) ; m\left(P_{R}\right)$-Pseudo pressure of formation pressure, $M P a^{2} /(m P a \cdot s) ; m\left(p_{w f}\right)$ -Pseudo pressure of bottom hole pressure, $\mathrm{MPa}^{2} /(\mathrm{mPa} \cdot \mathrm{s})$; $m\left(P_{s c}\right)$-Pseudo pressure of atmospheric pressure, $\mathrm{MPa}^{2} /(\mathrm{mPa} \cdot \mathrm{s}) ; T$-Formation temperature, $K ; \mu_{g}$ - Gas viscosity, mPa:s; Z-Gaseous z-factor; $\rho_{g}$ - Gas density, $\mathrm{Kg} / \mathrm{m}^{3} ; \mathrm{D}$-Non-Darcy flow factor, $\left(10^{4} \mathrm{~m}^{3} / \mathrm{d}\right)^{-1}$; $\beta$-Turbulent coefficient, $m^{-1} ; h$-Net pay thickness, $m$; $S$-Skin factor; $\phi$-Porosity; $\phi_{i}$-Initial porosity; $K$ -Permeability, $m d ; K_{i}$-Original Permeability, $m d ; r_{w}$ -Well bore radius, $m ; r_{e}$-Well controlled radius, $m ; Q_{g}$ - Gas production, $\mathrm{m}^{3} / d ; Q_{A O F}$-Open flow capacity, $10^{4}$ $\mathrm{m}^{3} / d ; A 、 B$-Coefficient. $M_{g}$ - The molar mass of the gas, $\mathrm{kg} / \mathrm{kmol}$

\section{References}

[1] Ostensen, R.W., "Micro crack permeability in tight gas sandstone", SPE 10924, 1983.

[2] Davies J.P. and Davies D.K., David K. Davies \& Assocs. Inc., "Stress dependent permeability characterization and modeling", SPE 71750, 2001.

[3] Zhu Z.Q., Wang Z.B., Li R.Y., Zhong Q., and Wang K., "Characteristics of the rock deformation in Abnormal high-Pressure gas reservoir and the studies of its influence on gas reservoir exploitation: example from the Kela2 gas field", Natural Gas Geoscience.

[4] Dong P.C., Jiang T.W., and Tang M.L., "Research on stress-sensitivity in abnormal high pressure gas reservoir", Chinese Journal of Rock Mechanics and Engineering, 2008, 27, (10), pp. 2087-2093.

[5] Xiang Y. and Xiang D., "An experimental study of simulating high-speed production in tight sandstone gas reservoir", Journal of Chengdu University of Technology, 2002, 29, (6), pp.617-619.
[6] Guo P., Zhang J., Du J.F., et al, "New way to improve gas well production condensate gas field's recovery factor", Journal of Southwest Petroleum University, 2007, 29, (2), pp.7-9.

[7] Yang S.L., Xiao X.J., Wang X.Q., et al, "Stress sensitivity of rock and its influence on productivity for gas reservoirs with abnormal high pressure", Natural Gas Industry, 2005, 25, (5), pp.94-95.

[8] Guo J.J., Zhang L.H. and Tu Z., "Stress sensitivity and its influence on productivity in gas reservoirs with abnormally high pressure", Special Oil \& Gas Reservoir, 2010, 17, (2), pp.79-81.

[9] Yang B., Jiang H.Q., Chen M.F., et al, "Diliverability equation for stress-sensitive gas reservoir", Journal of Southwest Petroleum University (Science \& Technology Edition), 2008, $30,(5)$, pp. 158-160.

[10] Fang Y. "Research on relationship between deliverability of gas reservoir and the stress-sensitiveness of the reservoir", Well Testing, 2009, 18, (6), pp.18-21.

[11] Xie Y.H., Zhang Y.Z., Li X.S., et al, "Main controlling factors and formation models of natural gas reservoirs with high-temperature and overpressure in Yinggehai Basin", Acta Petrolei Sinica, 2012, 33, (4), pp.601-609.

[12] Pei J.X., Yu J.F., Wang L.F., et al, "Key challenges and strategies for the success of natural gas exploration in mid-deep strata of the Yinggehai Basin”, Acta Petrolei Sinica, 2011, 32, (4), pp.573-579.

[13] Song W.J., Jiang T.W., Wang Z.B., Li R.Y., Feng J.L. and Zhu Z.Q., "Development techniques for abnormal high-pressure gas fields and condensate gas fields in Tarim Basin', SPE Asia Pacific Oil and Gas Conference and Exhibition, Perth, Australia, 18-20 October 2004.

[14] Li B.Z., Zhu Z.Q., Xia J., Ma C.Q., "Development patterns and key techniques of coal-formed Kela 2 gas field", Petroleum Exploration and Development, 2009, 36, (3), pp.392-397.

[15] Muhammad A., Amanat A.B., Ahmed S.K., and Syed A.H., "An alternative approach for well test analysis and production performance in tight gas reservoirs considering stress dependent permeability", SPE/PAPG Annual Technical Conference, Islamabad, Pakistan, 3-5 December 2012.

[16] Sun H.D., Xiao X.J., Yang J.P. and Zhang F., "Study on productivity evaluation and performance prediction method of overpressured stress-sensitive gas reservoirs", SPE Asia Pacific Oil \& Gas Conference and Exhibition, Jakarta, Indonesia, 30 October-1 November 2007.

[17] Li C.L, "Evaluation method for stress sensitivity of reservoir rock", Petroleum Geology \& Oilfield Development in Daqing, 2006, 25, (1), pp.40-42.

[18] He J.G., Kang Y.L., You L.J., et al, "Effects of mineral composition and microstructure on stress-sensitivity of mudrocks", Natural Gas Geoscience, 2012, 23, (2), pp.129-134.

[19] Du X.L., Kang Y.L., You L.J., et al, "Controlling Factors of Stress Sensitivity in Low-Permeability Reservoirs", Natural Gas Geoscience, 2010, 21, (2), pp.295-299. 